\title{
Practical use of the digital pedagogical activity simulator: efficiency, innovation, and experience
}

\author{
Alfinur Galiakberova ${ }^{1 *}$, Irina Zakharova ${ }^{1}$, Elmira Galyamova $^{1}$, and Oleg Chervov ${ }^{1}$ \\ ${ }^{1}$ Naberezhnye Chelny State Pedagogical University, 28, Nizametdinov str., 423806, Naberezhnye \\ Chelny, Russia
}

\begin{abstract}
The article presents the experience of developing and using the digital simulators in teaching and learning at a pedagogical university. Testing the innovative technologies in the course of teachers' training enables to conclude that this tool is effective when acquiring the professional competencies. The simulators, including the virtual ones, ensure modeling the pedagogical activity in terms of the principles of the activity approach. The analytical part of the article includes the content of the assessment criteria when planning and giving the classes on a digital simulator. The criteria for assessing the operations of a university student on the simulator are consistent with the requirements for the learning outcomes of schoolchildren. The results obtained confirm the relation between the labor operations performed by future teachers and the requirements established by the Federal State Educational Standards for universal learning skills (cognitive, communicative, and regulatory). The content of these requirements involves skills at searching for the study material and assuming the position of an active subject. The requirements content is consistent with the criteria for assessing the operations of the future teacher. The results of testing the simulator enable to analyze the advantages and disadvantages of using a digital simulator in teachers' training. Its use may involve making some changes in Teaching Methodology at a pedagogical university.
\end{abstract}

\section{Introduction}

The current development of the digital technologies and their implementation in the educational process at universities involve distance learning technologies when training the future teachers. In this regard, developing and testing the digital pedagogical activity simulator, which enables to combine theory with teaching practice, is of importance.

The Naberezhnye Chelny State Pedagogical University (NSPU) is carrying out a joint international project with the University of Reims Champagne-Ardennes (France). The ideas of creating a virtual classroom and simulating the educational process were disseminated during the seminars of Frederic Castel, the Director of the Pedagogical Institute of the University of Reims and the University branches in Troyes and Chaumont. In 2015 the first version of the mathematical simulator was demonstrated by Frederick Castel during his presentation at the conference held by the NSPU Faculty of Mathematics and Computer

\footnotetext{
* Corresponding author: ngpu.nis@gmail.com
} 
Science [1]. In his report, the French scientist emphasized the importance of that didactic tool when training the future teachers. The presented version of the simulator was created by a schematic representation of a virtual classroom in two-dimensional graphics. It modeled a fragment of the Geometry lesson on solving a construction problem. The virtual model is an analogue of the real educational process. The training model should highlight the most significant characteristics of the real educational process in terms of pedagogy, methodology and the subject (discipline). According to the project, 2-3-year students should gain teaching experience in a simulated environment that is as close as possible to the real one.

The project is aimed at creating a digital simulator of pedagogical activity. The project enables students to acquire competence in methodology when studying at a pedagogical university and diagnose their level prior to teaching a real class at school.

\section{Materials and methods}

The theoretical and methodological basis for the analysis of the effectiveness of virtual simulators in teachers' training is made up of the studies conducted by C. Frederick [1], M. Sharma [2], L. Carrington, L. Kerwin, and V. Ferry [3]. The models for developing and applying the digital simulators in the educational process are presented in the studies that are done by J.J. Chini, K.L. Straub, K.H. Thomas [4], L.A. Dieker et al. [5], M. Girod [6], E. Hixon [7], and J. Manburg [8].

A number of foreign and Russian researchers write that there is need for acquiring professional competencies in the course of virtual practice using simulators (O.P. Zhigalova, T.L. Kopus [9], V.L. Sokolov [10], and E. Galyamova [11]). The methodology competence in diagnosing the learning outcomes is acquired by applying the modular principle when implementing the professional educational program (I. Zakharova, E. Galyamova, etc.). The model for assessing the professional competencies in future teachers is presented in the studies conducted by S.N. Matveyev [12], A.O. Matlin [13], V.L. Sokolov, C. Frederik, and M. Sharma.

The purpose of this project is to test the Russian-language version of the French simulator when mastering future teachers' skill to analyze a lesson in terms of the activity approach. In addition, it is aimed at creating the original model of a lesson, which enables to train students in planning and designing the lesson. This simulator is based on the model for simulating learning activities.

The theoretical and methodological analysis of the simulator model shows that the criteria for assessing the professional skills reflect the basic principles of L.S. Vygotsky relating to students' development (zone of proximal development) [14]. This fact enables to affirmatively answer the question about the possibility of using the simulator in Russia's educational system. It has been found out by experiment that the simulator helps a student to take on the role of a virtual teacher (tutor) and to apply the principles of the activity approach.

The theoretical and methodological basis of the study is made up of the works on the role of men and women in the development of society (N.G. Chernyshevsky [3], V.S. Solovyov [4], N.A. Berdyaev [5], etc.); foreign and Russian theories of development and gender identification of the individual (Burn S.M. [6], Ward A.Z. [ibid.], Flandrin J.-L. [7], Maccoby E.E. [8], Jacklin C.N. [ibid.], T.K. Antonova [2], V. Vdovyuk [1], S. Rykov [ibid.], etc.); theoretical and practical studies of the issues of teaching pre-school children the gender identity (M.A. Radzivilova [9], N.E. Tatarintseva [10], A.M. Shchetinina [11], etc.).

The purpose of the study has been achieved within the framework of methodological approaches: the cultural approach (V.S. Bibler, E.V. Bondarevskaya, L.V. Kolomiychenko, I.S. Kon, etc.); the activity approach (L.S. Vygotsky, A.N. Leontyev, S.L. Rubinstein, D.B. Elkonin, L.I. Bozhovich, etc.); the environment approach (K.D. Ushinsky, S.T. Shatsky, A.S. Makarenko, V.A. Sukhomlinsky, V.G. Bocharova, A.V. Mudrik, etc.). The methodological 
reference point in the study is the gender approach. We share the point of view of E.N. Kamenskaya, “ $\ldots$ the gender approach in pedagogy is a methodological orientation in pedagogical activity that allows ensuring and supporting the processes of gender selfknowledge, self-building and self-realization of the child's personality, the development of the unique personality through a system of interrelated concepts, ideas and methods of actions. ..." [12].

The following methods have been used in the study: analysis of psychological, pedagogical, and socio-cultural literature, classification, comparison, generalization, systematization, experiment, observation, methods of mathematical statistics.

\section{Results}

Developing the innovative method involved several stages: at the first stage the French version of the simulator - a geometry lesson for eighth-grade students - was translated. The French version is based on a geometry problem on determining the center of a circle described near a triangle. The illustrations on the Geo Gebra platform are used to model a problem situation. In order to promote Russia's programs that are widely used by Mathematics teachers in this country, we have considered the possibility of combining the virtual simulator with the "Live Mathematics" ("Zhivaya Matematika") program as an analogue platform for "Geo Gebra" and "The Gejmeter's Sketchpad".

At the second stage the Russian-language version was tested under conditions of the Russian educational system. The stage involves standard procedures for testing the simulator as a methodology tool, studying its potential when training the students of Mathematics at Russia's pedagogical universities $[15,16]$.

At the third stage two original models of digital simulators were developed. The first model enables to assess the level of proficiency in designing a lesson. The second model is a digital simulator that enables to find out a strategy for searching for the solutions to mathematical problems and to teach how to search for the solutions to complex problems in class [17].

We will describe in more detail the procedure for testing the digital simulator of pedagogical activity.

It should be noted that any methodological product developed abroad and used in the Russian education system involves its relevance evaluation. This objective was attained through analyzing the methodological foundations and the consistency of the principles of functioning the French simulator with the Russian regulatory documents, as well as expert reviewing the content of the skills that are acquired by students.

In addition, if one draws a parallel with the requirements of the Teacher's Professional Standard, it turns out that the simulator enables future teachers to perform such a labor operation as "regular analysis of the lesson effectiveness and the approaches to teaching". Our study has found out that a student using the simulator compares different operations of both school students and teachers and learns to analyze the methodological techniques of teaching, as well as to highlight the components of the lesson aimed at achieving the learning outcomes. The simulator enables future teachers to master self-reflection skills that help to analyze both effective and unproductive operations of a virtual teacher.

Thus, the researchers (methodologists, practical teachers, university teachers) have found out that the simulator enables a future teacher to acquire skills that meet the requirements of the Teacher's Professional Standard.

The next stage of testing the Russian-language version of the simulator was to analyze the assessment criteria for the labor operations that are learnt on the simulator.

When completing the work on the simulator, the student, who has answered the questions on the operations performed, is shown a table with the criteria for their assessing. Here is a 
content analysis of these assessment criteria from the standpoint of the principles of the activity approach [Table 1] [18].

Table1. Criteria for Assessing Student's Operations on Digital Pedagogical Activity Simulator.

\begin{tabular}{|c|l|l|}
\hline № & \multicolumn{1}{|c|}{ Criterion } & \multicolumn{1}{c|}{ Content characteristics } \\
\hline 1 & Encouraging to think & $\begin{array}{l}\text { Communicating knowledge in a ready-made form or } \\
\text { encouraging a student to think and participate in search and } \\
\text { research activities. } \\
\text { The criterion is used to assess the method of the teacher's work } \\
\text { at the stage of setting the objective. }\end{array}$ \\
\hline 2 & $\begin{array}{l}\text { Highlighting the errors } \\
\text { and underlining them }\end{array}$ & $\begin{array}{l}\text { Highlighting the errors made or finding them; independent } \\
\text { searching for errors, making self-assessment and exercising self- } \\
\text { control as well as performing the optional learning operations. } \\
\text { Searching activity develops independent thinking. }\end{array}$ \\
\hline 3 & $\begin{array}{l}\text { Supporting or assessing } \\
\text { fontrolling or giving } \\
\text { freedom of choice }\end{array}$ & $\begin{array}{l}\text { Prompting a trainee or analyzing the trainee's operations; raising } \\
\text { teacher's open-ended questions to the closed ones (yes/no). } \\
\text { The open-ended questions enable to make larger answers. }\end{array}$ \\
\hline 5 & $\begin{array}{l}\text { Knowledge of didactic } \\
\text { constituents }\end{array}$ & $\begin{array}{l}\text { Controlling the virtual teacher's operations or giving the freedom } \\
\text { activity or as the object of pedagogical activity; the opportunity } \\
\text { for students to be independent when making decisions. }\end{array}$ \\
\hline $\begin{array}{l}\text { An integrated indicator of the level of proficiency in subject } \\
\text { knowledge of the topic being studied. }\end{array}$ \\
\hline
\end{tabular}

As you one see from the table, the criteria for assessing the trainee's operations on the simulator are consistent with the required learning outcomes of schoolchildren established by the state standard. Consistency has been found in the requirements of the state educational standard that are set in relation to the universal learning skills (cognitive, communicative, and regulatory). The content of these requirements involves demonstrating search skills when working with study material, taking the position of a subject, which are reflected in the criteria for assessing the operations of a future teacher.

One may consider the first, second and third criteria to be the cognitive universal learning skills. The second and third criteria relate to the communication skills. The second and the fourth criteria are regarded as the regulatory skills of self-control and self-management. As one can see, the assessment criteria for the operations performed on the simulator are integral and fully consistent with the acts regulating the content and the outcomes of teaching and learning at school and at university.

When completing the training course, each student is given an assessment list [Table 2]. The assessment list of one of the NSPU students is shown below.

Table 2. Assessment List Sample.

\begin{tabular}{|c|l|c|c|c|c|}
\hline № & \multicolumn{1}{|c|}{ Assessment criteria } & min & max & points & \% \\
\hline 1 & Encouraging to think & 0 & 61 & 31 & 50 \\
\hline 2 & Highlighting the errors and underlining them & 0 & 60 & 37 & 61 \\
\hline 3 & Supporting or assessing & 0 & 47 & 9 & 19 \\
\hline 4 & Controlling or giving freedom of choice & 0 & 52 & 17 & 32 \\
\hline 5 & Knowledge of didactic constituents & 0 & 53 & 25 & 47 \\
\hline
\end{tabular}

\section{Discussion}


As one can see from Table 2 , there is a minimum ( 0 points) indicator and a maximum one in the assessment list, i.e. the number of points that a student can get performing operations on the simulator (the range of indicators). The third column shows the individual number of points that the student has got while working on the simulator. As it is shown in the table, the maximum indicator is different for each criterion; therefore, to compare the level of skill proficiency, the indicators should be measured on the one-hundred-point rating system (the last column).

The student has the highest number of points for the second criterion (61 points), i.e. this student is likely to give the virtual teacher the opportunity to find the errors rather than to analyze them. This is the position of a mentor that immediately helps without showing the errors. The skill that is assessed by the first criterion has been formed at $50 \%$, i.e. when working on the simulator, the student sometimes chooses the options of a reproductive nature (communicates knowledge in a ready-made form) and in half of the cases the student chooses the operations aimed at thinking over and searching for information. The student is unlikely to support the virtual teacher but is likely to immediately assess its operations and perform the control function. This indicator also correlates with the level of the skill proficiency (assessed by the fourth criterion); our student chooses to control rather than to give freedom of choice. Thus, this student has not mastered the principles of the activity approach when analyzing a virtual teacher's lesson, but the student has knowledge of them (lack of minimum points for any of the criteria).

It should be noted that working on the simulator, students cannot know which option (correct or wrong) they use while thinking over a labor operation of the virtual teacher. The simulator is developed on the platform that enables to have a set of options when teaching to assume a reflective position.

The platform enables to repeatedly use the simulator in the course of training a future teacher. On the one hand, the correct operations are learnt while training on the simulator. On the other hand, they are learnt while studying the educational technologies at the classes in Teaching Methods. The work on the simulator should be combined with real practice. The modular principle of training future teachers is presented in the study [19]. Obviously, it is impossible to master the future teachers' competencies, which relate to the methods of teaching, in the virtual classroom. In other words, the integrated approach should be applied to the use of the simulator when teaching a student to assume the reflective position. Only virtual teachers will not ensure the learning outcomes.

In the course of testing the simulator the Mathematics teachers in Russia found out an interesting thing. The French colleagues consider two concepts - "actual perpendicular" and "abstract perpendicular" - which are not used in the Russian textbooks. It was necessary to study the content of the concepts and make a comparative analysis of how the subject is taught in France and in Russia. The discussions at the methodological seminars showed that "actual perpendicular" is a specific perpendicular constructed in a given figure. The perpendicular of this type is usually studied by schoolchildren to acquire the skill in constructing various shapes according to the specified properties. Meanwhile "abstract perpendicular" speaks of theoretical knowledge that enables schoolchildren to construct perpendiculars regardless of the shape and other context. Conceptual thinking involves a generalized learning operation, so the French teachers differentiate the concepts at the virtual lesson.

This fact has led to the conclusion that when developing our own simulator designed to train Mathematics teachers both in Russia and France, it is necessary to take into account the peculiarities of the educational systems, the national standards, and the training programs of each country. We understand that it is impossible to develop a simulator that will work equally effectively in each of the countries. Both Russian and French version of the simulator should be consistent with the national educational systems. 
Thus, the comparative analysis of the content of the virtual lesson, as well as the acquired labor operations and their assessment according to the criteria described above, has shown that the digital simulator developed by the French colleagues is not just its updated Russian version. As a result of the testing, the model of the methodology system of professional training has been developed. It takes into account the Russian standards of teaching and learning using the educational technologies that are aimed at mastering the competencies of future teachers.

The next stage of our study was focused on the following questions: does a university student gain new knowledge in the course of training on the simulator? Does a university student interiorize new teaching operations? Is the gained experience useful in real teaching practice? In other words, is there need to find out the relationship between the student's experience in working on the simulator and real practice?

The diagnostic study was conducted to clear up the above questions. 100 students of the NSPU Faculty of Mathematics and Computer Science and 30 Mathematics teachers with at least 5 years' experience in teaching participated in the study. Students' diagnostic procedure involved several stages. The students, who had studied Teaching Methods, were trained on the simulator prior to having teaching practice at school, as well as after coming back to studies.

The Mathematics teachers were tested in order to receive the feedback. The teachers were asked if the simulator was effective as a methodological tool. In addition, the testing was aimed at confirming the validity and reliability of the simulator as a diagnostic tool designed to find out the level of skill proficiency.

R. Kettell's screening criterion (screen-test) was applied to assess the quality of the students' reflective skills. The eigenvalue charts (Screen plot) given below show the results of the statistical data [Figure 1].

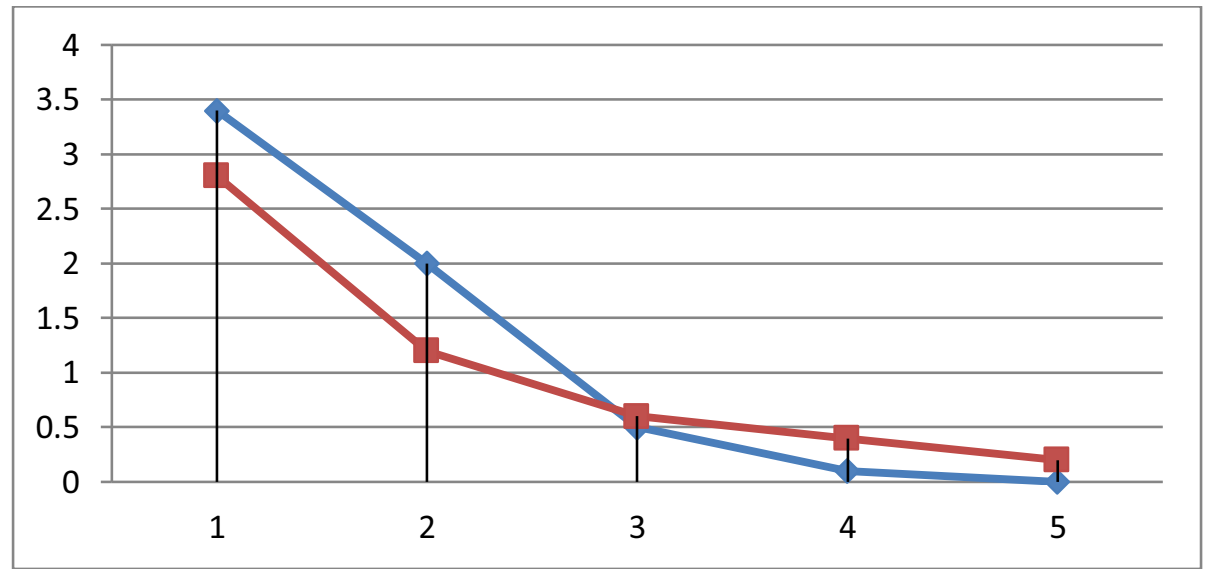

Fig. 1. Chart of eigenvalues (blue line - before the practical training; red line - after the practical training).

As one can see from the chart, prior to having teaching practice at school the first two components (criteria) were the key ones for the students, i.e. the rest criteria were not of importance to them.

Thus, the reflective components such as "communicating knowledge or encouraging selfreflection" and "highlighting the errors and underlining them" were highly significant for the students when analyzing the virtual lesson. Meanwhile the other three components (supporting and assessing, controlling the operations or giving freedom of choice, and knowledge of didactic constituents) were considered to be insignificant when performing the operations on the simulator. That could be explained by the fact that the students did not 
attach importance to those reflective components due to their incompetence, inability to "see" them at the virtual lesson, to identify the methodology units of the virtual teacher's operations.

The range of individual indicators prior to teaching practice at school is wider than after the practice. In other words, the variability zone of the individual indicators is high. We can see that among the students there are those who demonstrate high-level reflective skills. However, there are also students with low-level skills.

After the teaching practice at school the number of significant components increased, i.e. greater importance was also attached to the other criteria. The chart shows that the polyline becomes smoother and tends to be straight. The fact is that the students become aware of the significance of each criterion, i.e. they differentiate the concepts under study. The range of individual indicators becomes narrower and this confirms that the students acquire and demonstrate the skills that are consistent with the criteria.

The statistical data gathered in the course of the testing enable to confirm that the simulator is a diagnostic tool that helps to differentiate the skills acquired by the students. Taking into account the individual outcomes of students, as well as the level of their proficiency skills, a university teacher has an opportunity to develop the reflective skills [20].

It is clear that there should be a control group of students to confirm the reliability of the diagnostic procedures of the testing. Since our study did not set such an objective, all the participants of the experiment were trained using the simulator.

To confirm the results of the study, we have compared the outcomes of the students and the outcomes of the teachers with the first qualification category (working experience up to 5 years). The teachers' knowledge of didactic constituents is significantly greater. However, the students show the best skills in "controlling the operations or giving freedom of choice". This result can be explained as follows: the innovative technologies applied in this higher educational institution enable the students to master the skills.

The results of testing the Russian-language version of the simulator have led to the following conclusions. Firstly, the simulator can be used as a diagnostic tool, i.e. to find out the level of proficiency skills at analyzing the teacher's methodological operations in class and distinguishing different approaches to learning and teaching. Secondly, it can be also used as a simulator helping the students to acquire and master their professional skills.

Although the simulator trains students in teaching Geometry, it can be also used in other subject areas and disciplines that are taught at the university. In addition, the simulator can be useful when studying the innovative teaching technologies, the principles of the activity approach, and the methodic techniques and methods of teaching. For example, when studying the reflective positions of the virtual teacher, the university teachers explain the principles of lesson analysis established by the Federal State Educational Standard and the Teacher's Professional Standard. It is well known that the knowledge of these components is necessary in any subject area as teachers should analyze their own operations and the learning operations of their students.

\section{Conclusions}

The testing of the Russian-language version of the digital pedagogical activity simulator is completed and we can recommend using this innovative product in the educational process when training future teachers.

Thus, different types of simulators, designed to solve a variety of methodological problems, might be used in combination with real practice. They may fundamentally change the whole system of teachers' training at pedagogical universities in Russia.

Currently, in the framework of a joint project with the French colleagues a group of university researchers is developing the original model of a Math lesson (for 2nd and 5th 
grades) using the innovative educational technologies. The procedure is as follows: first, the Russian version of the lesson is developed, and then it is translated into French and adapted to the French educational model. It should be added that the mathematical content is determined by the universality of Mathematics and the possibility of transferring the simulation to another country without additional methodological improvement. But this does not mean that the digital simulator only enables to develop skills at Mathematics.

The simulator, as it is shown above, is a universal tool that enables to load any subject content and any labor operation in the digital format. This is confirmed by the fact that the original model includes some other labor operations from the Teacher's Professional Standard such as "planning and giving lessons" and "monitoring and assessing the learning achievements, current and final outcomes when mastering the educational program". Using the simulator, the student will be trained in designing and giving lessons.

Thus, the digital simulator is a universal methodological tool that enables to use any subject content (Mathematics, Russian, Geography, History, etc).

In addition, such simulators enable future teachers in different subject areas to be trained in performing other labor operations (along with analyzing the effectiveness of lessons and approaches to teaching; planning and giving classes).

Finally, it is important to note that the testing has found out another function of the simulator (in addition to practising the labor operations). The digital simulator enables to determine the level of the acquired competence, i.e. it can be used as a diagnostic instrument since its validity and reliability have been tested in practice.

The results of the experiment confirmed the hypothesis and allowed us to formulate the following findings:

1. Masculinity as a moral and psychological quality of a male is a generalizing characteristic of a personality. The "masculinity" concept involves such qualities as strength, courage, self-control, determination, honesty and justice. Masculinity cannot be formed without taking into account the psychological specifics of gender as it is developed when imitating.

2. The process of teaching boys the qualities of masculinity will be effective if the following conditions are met: creating a gender-functional subject-developing environment; involving children in different types of activities and communication that reflect gender standards; improving the gender competence of teachers and parents.

The work done at the present stage allows us to state that the purposeful process of pedagogical support of a preschooler that involves accumulating the gender experience should be continued. This intention makes it possible to set new objectives to gain broader experience of children's performing the gender roles and identifying themselves as representatives of their own sex at the stage of early childhood.

The article was written in accordance with the state assignment of the Russian Federation Ministry of Education «Scientific and methodological support for the development of digital competencies of teachers in rural schools within the framework of the implementation of additional education for students programs " (applied research, 2021).

\section{References}

1. C. Frederic, Current Problems of Mathematical Education: Materials of the Scientific and Practical Conference Dedicated to the 25th Anniversary of the Faculty of Mathematics and Computer Science, 164-175 (NSPU, Naberezhnye Chelny, 2015)

2. M. Sharma, Journal of Education and Practice, 6(4), 11-14 (2015)

3. L. Carrington, L. Kervin, B. Ferry, Journal of Technology and Teacher Education, 19, 351-368 (2011) 
4. J.J. Chini, C.L. Straub, K.H. Thomas, Physical Review Physics Education Research, 12(1), 010117-1-010117-15 (2016)

5. L.A. Dieker, J.A. Rodriguez, B. Lignugaris-Kraft, M. Hynes, C. Hughes, The Journal of the Teacher Education 37(1), 21-23 (2014)

6. M. Girod, G.R. Girod, Journal of Technology and Teacher Education, 16(3), 307-337 (2008)

7. E. Hixon, Educational Technology \& Society, 12(4), 294-304 (2009)

8. J. Manburg, R. Moore, D. Griffin, M. Seperson, Contemporary Issues in Technology and Teacher Education, 17(1), 128-153 (2017)

9. O.P. Zhigalova, T.L. Kopus, Current Problems of Science and Education 3, 141 (2018)

10. V.L. Sokolov, Psychological and Pedagogical Research 10(1) 127-135 (2018)

11. E.Kh. Galyamova, Teacher of the XXI Century 1(1), 153-159 (2019)

12. S.N. Matveyev, G.R. Antropova, Problems of Modern Pedagogical Education 61(1), 174- 177 (2018)

13. A.O. Matlin, Abstract of the Thesis of the Candidate of Technical Sciences (Volgograd, 2012)

14. L.S. Vygotsky, Thinking and Speech (Labyrint, Moscow, 1999)

15. E.Kh. Galyamova, Materials of the Russia's Scientific and Methodological Conference, 173-176 (NSPU, Naberezhnye Chelny, 2020)

16. E.Kh. Galyamova, Journal of History Culture and Art Research, 8(4), 371-381 (2019)

17. E.Kh. Galyamova, Teacher of the XXI century 4(1), 144-151 (2018)

18. A.A. Galiakberova, I.M. Zakharova, E.Kh. Galyamova, O.B. Chervov, Baltic Humanitarian Journal 4(33), 34-38 (2020)

19. I.M. Zakharova, Psychological and Pedagogical Research 10(1), 104-115 (2018)

20. S.N. Matveyev, G.R. Antropova, World of Science 5(2), 1-8 (2017) 